\title{
Chapter 21 \\ Options of Principles of Fuel Debris \\ Criticality Control in Fukushima Daiichi \\ Reactors
}

\author{
Kotaro Tonoike, Hiroki Sono, Miki Umeda, Yuichi Yamane, \\ Teruhiko Kugo, and Kenya Suyama
}

\begin{abstract}
In the Three Mile Island Unit 2 reactor accident, a large amount of fuel debris was formed whose criticality condition is unknown, except the possible highest ${ }^{235} \mathrm{U} / \mathrm{U}$ enrichment. The fuel debris had to be cooled and shielded by water in which the minimum critical mass is much smaller than the total mass of fuel debris. To overcome this uncertain situation, the coolant water was borated with sufficient concentration to secure the subcritical condition. The situation is more severe in the damaged reactors of Fukushima Daiichi Nuclear Power Station, where the coolant water flow is practically "once through." Boron must be endlessly added to the water to secure the subcritical condition of the fuel debris, which is not feasible. The water is not borated relying on the circumstantial evidence that the xenon gas monitoring in the containment vessels does not show a sign of criticality. The criticality condition of fuel debris may worsen with the gradual drop of its temperature, or the change of its geometry by aftershocks or the retrieval work, that may lead to criticality. To avoid criticality and its severe consequences, a certain principle of criticality control must be established. There may be options, such as prevention of criticality by coolant water boration or neutronic monitoring, prevention of the severe consequences by intervention measures against criticality, etc. Every option has merits and demerits that must be adequately evaluated toward selection of the best principle.
\end{abstract}

Keywords Criticality control • Fuel debris • Fukushima Daiichi

\subsection{Introduction}

In normal nuclear facilities, the goal of criticality control is to secure subcritical conditions of fissile materials, which is achieved by regulating the composition, geometry, or mass of the fissile materials [1]. In the accident of Three Mile Island

K. Tonoike $(\bowtie) \bullet$ H. Sono $\bullet$ M. Umeda $\bullet$ Y. Yamane $\bullet$ T. Kugo $\bullet$ K. Suyama Japan Atomic Energy Agency, 2-4 Shirakata Shirane, Tokai, Ibaraki, 319-1195, Japan e-mail: tonoike.kotaro@jaea.go.jp 
Unit 2 reactor (TMI-2), heavily damaged and melted fuel assemblies formed a large amount of fuel debris whose composition was unknown except the possible highest ${ }^{235} \mathrm{U} / \mathrm{U}$ enrichment, $3 \mathrm{wt} \%$, whose geometry is uncertain, and whose mass is larger than the minimum critical mass derived from the enrichment. Moreover, the fuel debris had to be cooled and shielded by water. To overcome this uncertain situation, the coolant water was borated with a concentration, $>4,350 \mathrm{ppm}$, sufficient to secure the subcritical condition [2].

The situation of the damaged reactors in Fukushima Daiichi Nuclear Power Station (1FNPS) is more severe than that of TMI-2 because of the water issue. The most major difference is that the coolant water flow is practically "once through." Boron should be ceaselessly added in the water to maintain its lowest concentration necessary to secure the subcritical condition, which is not feasible. The water is not borated relying on the circumstantial evidence that the xenon gas monitoring in the containment vessels (CVs) does not show a sign of criticality. Although the fuel debris will not be touched for a while, its condition may change because of a gradual drop of its temperature or change of its geometry by aftershocks. The condition will be intentionally changed when the fuel debris is retrieved. Every such change may lead to the criticality of fuel debris [3].

To avoid criticality and its severe consequences, a certain principle of criticality control must be established. There may be options, such as prevention of criticality by coolant water boration or by neutronic monitoring, prevention of the severe consequences of criticality, etc. Each has merits and demerits.

It is necessary to understand the actual condition of the fuel debris regarding the selection of an appropriate principle from those options and the realization of certain criticality control following the selected principle. Adequate observation, sample taking, and analysis of the fuel debris must be conducted.

\subsection{Present Condition of 1FNPS Fuel Debris}

Fuel assemblies with the design called "BWR STEP 3" had been loaded in the reactors. Each new fuel assembly contains six kinds of uranium dioxide $\left(\mathrm{UO}_{2}\right)$ fuel (Fig. 21.1, Table 21.1). The most popular initial ${ }^{235} \mathrm{U} / \mathrm{U}$ enrichment in the fuels is $4.4 \mathrm{wt} \%$, whose inventory per assembly is $76.8 \mathrm{kgU}$. The fuel of $9.6 \mathrm{kgU}$ per assembly has the highest initial enrichment of $4.9 \mathrm{wt} \%$. The initial uranium inventory in total is $170.9 \mathrm{kgU}$ per assembly, including fuels of other enrichments and of the $\mathrm{UO}_{2}$-gadolinium oxide $\left(\mathrm{Gd}_{2} \mathrm{O}_{3}\right)$ composite [4].

The Unit 1 reactor in 1FNPS had 400 assemblies, which consisted of six batches of burn-up. Each of the Unit 2 and 3 reactors had 548 assemblies of five batches. Among these assemblies, 64 in the Unit 1 reactor, and 116 in the Unit 2 reactor, had a low burn-up of only 3-5 GWD/t (Table 21.2). Other assemblies of the same number are older but still have a burn-up as low as 15-16 GWD/t. The oldest assemblies have a burn-up of about $40 \mathrm{GWD} / \mathrm{t}$ [5]. 


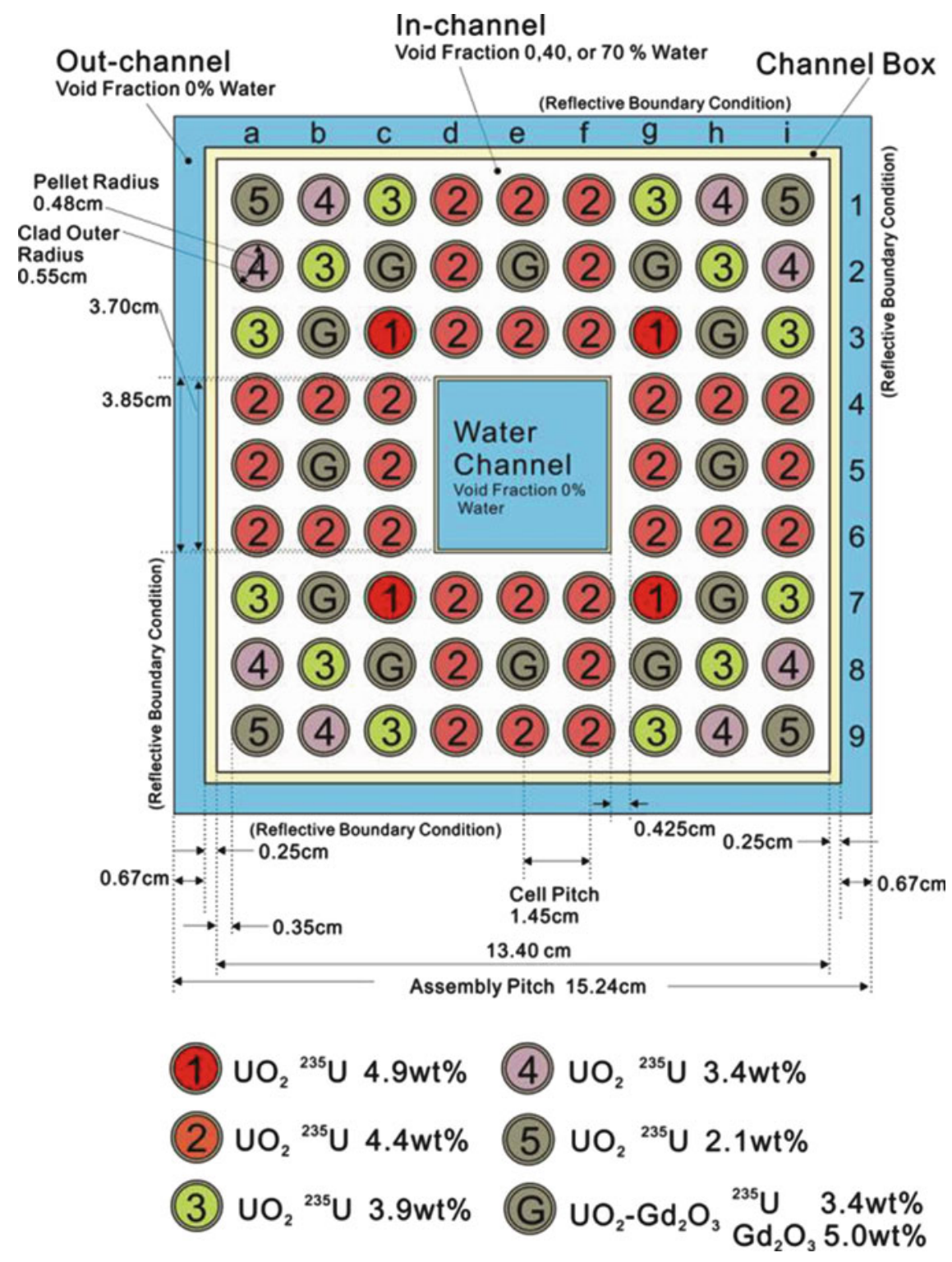

Fig. 21.1 Benchmark model of the BWR STEP3 fuel assembly

The condition of the fuel debris has not yet been identified in any reactor except estimations by severe accident analysis codes. Study of the TMI-2 fuel debris [6], however, suggests that various kinds of fuel debris may also be produced in the 1FNPS reactors, such as hard and loose debris. Especially, loose debris may show a wide variety of composition including structural materials such as Zircaloy and 
Table 21.1 Initial uranium inventory in a boiling water reactor (BWR) STEP 3 fuel assembly

\begin{tabular}{l|c}
\hline${ }^{235} \mathrm{U} / \mathrm{U}$ enrichment & Mass $(\mathrm{kgU})$ \\
\hline $4.9 \mathrm{wt} \%$ & 9.6 \\
\hline $4.4 \mathrm{wt} \%$ & 76.8 \\
\hline $3.9 \mathrm{wt} \%$ & 28.8 \\
\hline $3.4 \mathrm{wt} \%$ & 19.2 \\
\hline $2.1 \mathrm{wt} \%$ & 9.6 \\
\hline $3.4 \mathrm{wt} \%\left(\mathrm{with}_{\left.\mathrm{Gd}_{2} \mathrm{O}_{3}\right)}\right.$ & 26.9 \\
\hline Total & 170.9 \\
\hline
\end{tabular}

Table 21.2 Burn-ups of fuel assemblies in the 1FNPS reactors

\begin{tabular}{l|l|l}
\hline Unit 1 & Unit 2 & Unit 3 \\
\hline $5.2: 64$ & $3.3: 116$ & $4.7: 148^{\mathrm{a}}$ \\
\hline $15.2: 64$ & $15.8: 116$ & $15.5: 112$ \\
\hline $24.2: 80$ & $26.0: 120$ & $28.5: 140$ \\
\hline $33.3: 68$ & $35.2: 120$ & $36.2: 112$ \\
\hline $37.5: 64$ & $40.6: 76$ & $40.5: 36$ \\
\hline $40.2: 60$ & (GWD/t, number of assemblies) \\
\hline
\end{tabular}

${ }^{\mathrm{a}} 16$ MOX assemblies included

steel. Boron originating from the control rods cannot be expected necessarily to coexist with the fuel debris. It is also possible that the fuel debris in CVs has been generated through the molten core-concrete interaction (MCCI). It must be considered that the fuel debris is not uniform and will be found at various locations.

The fuel debris is being cooled with nonborated water although it is highly preferable to add neutron poison and to maintain enough concentration in the water to secure the subcritical condition such as was performed after the TMI-2 accident. Boration is not realistic at present because of the coolant water leakage from CVs and underground water inflow to the coolant water circulation. Boron will be injected only in the event of re-criticality [7].

\subsection{Criticality Characteristics of Fuel Debris}

The criticality safety handbook shows the minimum critical masses of homogeneous uranium-water mixtures, 36 and $53 \mathrm{~kg}$, respectively for the ${ }^{235} \mathrm{U} / \mathrm{U}$ enrichments of 5 and $4 \mathrm{wt} \%$. Mass control limits that can avoid criticality are also given for heterogeneous $\mathrm{UO}_{2}$-water composites, that is, $28 \mathrm{~kg}$ for the $5 \mathrm{wt} \%$ enrichment. Even for the $3 \mathrm{wt} \%$ enrichment, its mass limit is still $67 \mathrm{~kg}$ [8]. These numbers are small compared to the possible uranium inventory in each fuel assembly with low burn-up.

Fuel debris may exist as composites of $\mathrm{UO}_{2}$ and structural materials such as Zircaloy and steel in the pressure vessels (PVs). Zircaloy does not greatly affect the criticality characteristics of fuel debris because of its small neutron absorption cross 
section, but the iron in steel may increase the critical mass of fuel debris because it has strong neutron absorption.

The MCCI product would be a composite of $\mathrm{UO}_{2}$ and concrete. The major content of concrete is silicon dioxide, which has also a small neutron absorption cross section and neutron moderation capability. The critical mass of the $\mathrm{UO}_{2}-$ concrete composite has been evaluated as $400 \mathrm{~kg}$ for the fresh $\mathrm{UO}_{2}$ of $5 \mathrm{wt} \%{ }^{235} \mathrm{U} / \mathrm{U}$ enrichment. For the fuel burned up to $12 \mathrm{GWD} / \mathrm{t}$, the critical mass can be as small as 800 or $2,000 \mathrm{~kg}$, depending on how the effect of fission products is considered. Only the water bonded in concrete is considered in the evaluation; therefore, the critical masses can be smaller when the MCCI product is submerged in the coolant water [9]. The mass of $2,000 \mathrm{~kg}$ is equivalent to 12 fuel assemblies. It is also known that a certain cluster of 16 assemblies in the Unit 2 reactor has an average burn-up of about $14 \mathrm{GWD} / \mathrm{t}$. Thus, this evaluation is not far from reality.

Before knowing the actual condition of fuel debris, it is possible to compute critical conditions. Such work has been already conducted for many years to produce a handbook or a database for criticality safety. It is easy to extend these standards to wider conditions such as $\mathrm{UO}_{2}$-steel composite or $\mathrm{UO}_{2}$-concrete composite. The computation will supply a new set of "criticality maps of fuel debris." These maps will indicate (Fig. 21.2) subcritical and critical conditions, and supercritical conditions that would likely bring severe consequences. In Fig. 21.2, the horizontal line represents variation of composition, and the vertical line represents variation of geometry. Composition on the right has higher reactivity and smaller critical volume. On the left, the composition is certainly subcritical, which can be excluded from the criticality control.

The actual criticality situation will be assessed by placing onto the map the fuel debris condition revealed by observations or sample analyses. It is also necessary to study how the condition can move on this map from expected changes such as temperature drop in the fuel debris or geometry changes caused by retrieval work of fuel debris, etc.

\subsection{Options of Criticality Control Principles}

\subsubsection{Prevention of Criticality by Poison or Dry Process}

The boration of coolant water was practiced in TMI-2 and is most preferable. Borated water bounds the criticality characteristics of all debris into a small region, indicated as "Boration" in Fig. 21.3, and keeps the region far from critical condition no matter how much temperature or geometry changes. By securing the lowest boron concentration in water, the subcritical condition can be guaranteed as well. The water issue, however, must be fixed to implement this option. Moreover, a structure made of carbon steel or aluminum will act as the water boundary when a 


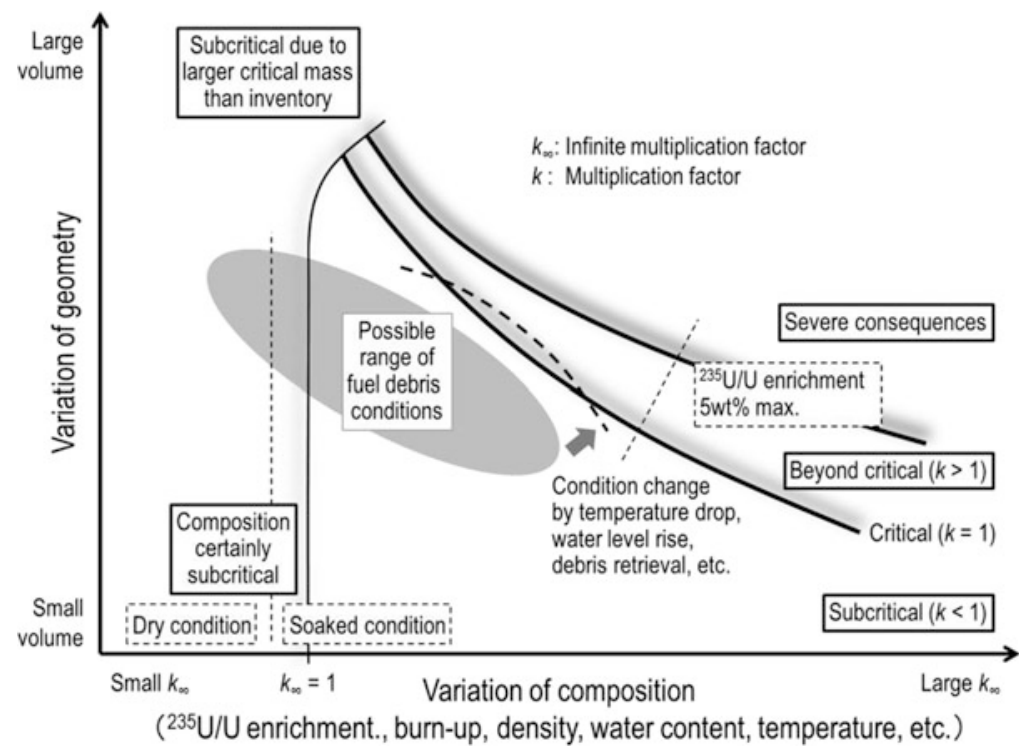

Fig. 21.2 Criticality map of fuel debris

$\mathrm{CV}$ is filled with water. Then, corrosion of such material by boron must be studied to prevent recurrence of the water issue.

The dry process without using coolant water will be also a certain criticality control method (Fig. 21.3). There will be, however, other engineering challenges. CVs must be sealed to avoid unexpected intrusion of water. It will be necessary as well to shield radiation and to suppress airborne migration of radioactive materials without water during fuel debris retrieval work.

\subsubsection{Prevention of Criticality by Monitoring}

Utilization of borated water may not be feasible if the water issue cannot be remedied. An alternative may be subcriticality monitoring. It is necessary to detect the signs of approach to the critical condition across the defense line set in the subcritical region in Fig. 21.4, and an intervention measure must be deployed quickly before the critical condition is reached. Detection may be possible by setting neutron counters near the fuel debris.

There are key natures of the intervention measure to be understood. The injection of neutron poison is the only way, and it will be realistic only if the actual condition of fuel debris is far from critical condition. It will be, however, difficult to make the defense line effective if the buffer zone is small. To retain the effect of intervention even after the event, the neutron poison concentration must be maintained in the coolant water. 


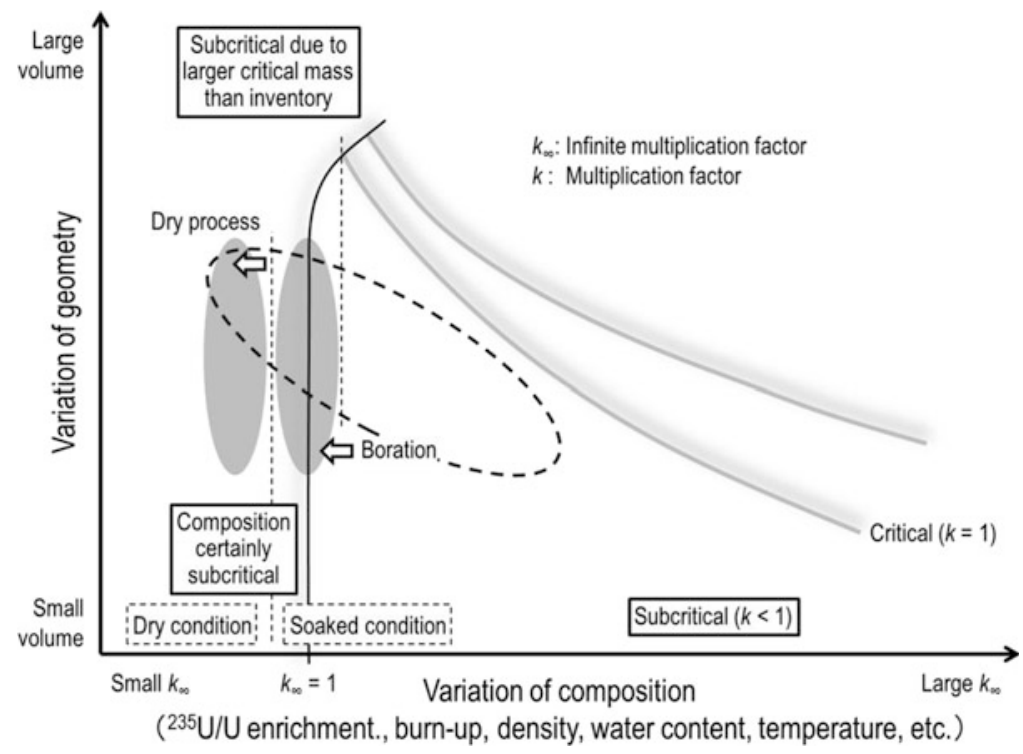

Fig. 21.3 Prevention of criticality by boration or dry process

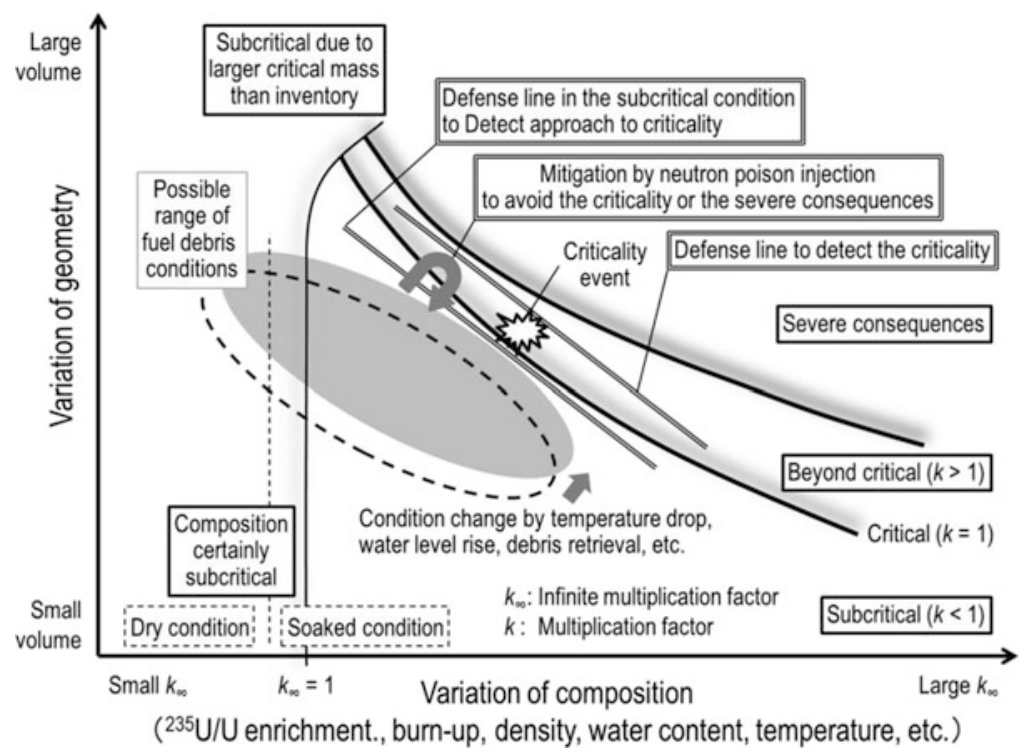

Fig. 21.4 Prevention of criticality and the severe consequences by monitoring 
Thus, this option does not differ, essentially, from the first option, which is prevention of criticality by poison. Monitoring still makes sense if we integrate it with the first option and use it as an implementation of the "double contingency principle."

\subsubsection{Prevention of Severe Consequence}

The last option is, in fact, being currently applied. The defense line consists of xenon gas monitoring and the injection of borated water. The monitoring sensitivity is not sufficient to measure subcriticality but can detect the event beyond the occurrence of critical condition before severe consequences result. The borated water on standby will be injected when the monitoring detects the criticality. A study is under way to improve the monitoring sensitivity to make the detection and intervention quicker and to reduce the risk of this option.

A much bolder idea is also being brought up, which is to consider such quick detection and intervention as a regular reactivity control. A small-scale, controlled chain reaction is permissible in the concept, and the resumption of fuel debris retrieval is allowed after suppressing the criticality. To realize this kind of criticality control, its risk must be fully understood.

\subsubsection{Risk Assessment}

The risk study is necessary regardless of which option is chosen because the subcritical condition is not secured at present. Even though the fuel debris will not be touched for a while, the temperature of the fuel debris may drop gradually in time, which slowly increases reactivity. The risk of "low probability and high consequence events" must be also evaluated. An aftershock of large magnitude may change the fuel debris geometry greatly. The extreme event would be the fall of fuel debris in the PV onto the other in CV.

The fuel debris retrieval must be assessed carefully, of course, if it is conducted under nonborated water. The first step of the risk analysis is to understand the actual conditions of fuel debris. Exhaustive observation of the fuel debris should be conducted as early as possible, which enables us to complete the maps described in the previous sections.

According to each option, engineering work should be performed in parallel to establish design requirements. For the prevention of criticality by borated water, its required lowest concentration must be established. For the prevention of criticality by monitoring, requirements of sensitivity and time response of the monitoring and time response of an intervention measure must be clarified. For the prevention of severe consequences, an allowable limit of fission number must first be set. Then, the time response of detection and intervention must be defined to regulate fission numbers of supposed criticality events within the limit. 


\subsection{Conclusions}

In 1FNPS, fuel debris conditions in the three damaged reactors are still unknown and uncertain. The water issue also affects criticality control, as the coolant water is not borated. Although fortunately no sign of criticality has yet been seen, the subcritical condition is not secured. There are options of principles to pursue a certain critical control of the fuel debris: prevention of criticality by poison, by dry process, or by monitoring, and prevention of the severe consequences resulting from criticality. Engineering research and development is to be conducted regarding any of these options.

Open Access This chapter is distributed under the terms of the Creative Commons Attribution Noncommercial License, which permits any noncommercial use, distribution, and reproduction in any medium, provided the original author(s) and source are credited.

\section{References}

1. Japan Atomic Energy Research Institute (2005) Working Group on Nuclear Criticality Safety Data. Nuclear criticality safety handbook, version 2. JAERI-1340. Japan Atomic Energy Research Institute (in Japanese)

2. Stratton WR (1987) Review of the state of criticality of the Three Mile Island Unit 2 core and reactor vessel. DOE/NCT-01, Lawrence Livermore National Laboratory, California, United States of America

3. Tonoike K et al (2013) Major safety and operational concerns for fuel debris criticality control. In: Proceedings of the GLOBAL 2013: International nuclear fuel cycle conference, Salt Lake City, UT, September 29-October 3, 2013

4. Suyama K et al (2012) OECD/NEA burnup credit criticality benchmark phase IIIC. Nuclide composition and neutron multiplication factor of BWR spent fuel assembly for burnup credit and criticality control of damaged nuclear fuel. OECD/NEA/WPNCS/EGBUC, Paris, France

5. Nishihara K et al (2012) Estimation of fuel composition in Fukushima-Daiichi nuclear power plant. JAEA-Data/Code 2012-018, Japan Atomic energy Agency (in Japanese), Ibaraki, Japan

6. Akers DW et al (1992) TMI-2 examination results from the OECD-CSNI Program. NEA/CSNI/ $\mathrm{R}(91) 9$. Committee on the safety of nuclear installations, Organization for Economic Cooperation and Development, Paris, France

7. Tokyo Electric Power Company, Inc. (2011) Status of Fukushima Daiichi nuclear power station. http://www.tepco.co.jp/en/nu/fukushima-np/index-e.html

8. Okuno $\mathrm{H}$ et al (2009) Second version of data collection part of nuclear criticality safety handbook (Contract Research). JAEA-Data/Code 2009-010, Japan Atomic Energy Agency, Ibaraki, Japan

9. Izawa $\mathrm{K}$ et al (2012) Infinite multiplication factor of low-enriched $\mathrm{UO}_{2}$-concrete system. J Nucl Sci Technol 49(11):1043 